Biogeosciences, 10, 5517-5531, 2013

www.biogeosciences.net/10/5517/2013/

doi:10.5194/bg-10-5517-2013

(C) Author(s) 2013. CC Attribution 3.0 License.

\title{
Autonomous, high-resolution observations of particle flux in the oligotrophic ocean
}

\author{
M. L. Estapa ${ }^{1}$, K. Buesseler ${ }^{1}$, E. Boss ${ }^{2}$, and G. Gerbi ${ }^{3}$ \\ ${ }^{1}$ Department of Marine Chemistry and Geochemistry, Woods Hole Oceanographic Institution, Woods Hole MA, USA \\ ${ }^{2}$ School of Marine Sciences, University of Maine, Orono ME, USA \\ ${ }^{3}$ Departments of Physics and Geosciences, Skidmore College, Saratoga Springs NY, USA
}

Correspondence to: M. L. Estapa (mestapa@whoi.edu)

Received: 11 January 2013 - Published in Biogeosciences Discuss.: 28 January 2013

Revised: 28 June 2013 - Accepted: 1 July 2013 - Published: 16 August 2013

\begin{abstract}
Observational gaps limit our understanding of particle flux attenuation through the upper mesopelagic because available measurements (sediment traps and radiochemical tracers) have limited temporal resolution, are labor-intensive, and require ship support. Here, we conceptually evaluate an autonomous, optical proxy-based method for high-resolution observations of particle flux. We present four continuous records of particle flux collected with autonomous profiling floats in the western Sargasso Sea and the subtropical North Pacific, as well as one shorter record of depth-resolved particle flux near the Bermuda Atlantic Time-series Study (BATS) and Oceanic Flux Program (OFP) sites. These observations illustrate strong variability in particle flux over very short ( $\sim$ 1-day) timescales, but at longer timescales they reflect patterns of variability previously recorded during sediment trap time series. While particle flux attenuation at BATS/OFP agreed with the canonical power-law model when observations were averaged over a month, flux attenuation was highly variable on timescales of 1-3 days. Particle fluxes at different depths were decoupled from one another and from particle concentrations and chlorophyll fluorescence in the immediately overlying surface water, consistent with horizontal advection of settling particles. We finally present an approach for calibrating this optical proxy in units of carbon flux, discuss in detail the related, inherent physical and optical assumptions, and look forward toward the requirements for the quantitative application of this method in highly timeresolved studies of particle export and flux attenuation.
\end{abstract}

\section{Introduction}

Particles settling into the deep ocean remove carbon and biologically important trace elements from sunlit, productive surface waters and from contact with the atmosphere over short timescales. The ultimate fate of this particulate carbon, be it remineralization in the "twilight zone" or deposition among seafloor sediments, depends on a shifting balance among physical, chemical, and biological processes. Sparse observations show variable patterns in the timing and strength of this particle flux, with about $90 \%$ of sinking carbon being consumed in the upper $1.5 \mathrm{~km}$ of the ocean (Martin et al., 1987). To tease apart the balance among the processes controlling the flux of carbon to the deep ocean requires both broader and more highly time-resolved estimates of the settling particle flux, particularly in the upper ocean just below the euphotic zone, where most remineralization occurs.

Current methods for assessing particulate carbon export in the upper ocean include direct measurements with sediment traps (Gardner, 2000; Buesseler et al., 2007), proxy measurements using surface-ocean ${ }^{234} \mathrm{Th}$ deficits (BenitezNelson and Moore, 2006; Buesseler et al., 1992), and indirect inference from measurements of upper-ocean elemental balances (Emerson et al., 1997; Michaels et al., 1994) and deep microbial respiration (Burd et al., 2010). None of these methods resolve flux at timescales shorter than $24 \mathrm{~h}$, and upperocean sediment trap deployments are generally limited to lengths of just a few days. All of these methods are labor- and ship-time-intensive; thus the spatial coverage of particle flux observations is restricted to a few sites, and long-term temporal coverage is further limited to a handful of time-series programs. 
Several recent studies suggest that much of the variability in particulate carbon fluxes arises on short spatiotemporal scales - tens of kilometers and periods of days. Using estimates of carbon flux based on water-column ${ }^{234} \mathrm{Th}$ deficits, Buesseler et al. (2009) found that short-timescale variability in export exceeds seasonal variability in the North Pacific, and that sediment trap flux measurements were not long enough to integrate the flux signal. For drifting traps in the same study, Siegel et al. (2008) computed the surface source locations and trajectories of collected particles, and found that "source funnels" for upper-ocean traps were narrow (on the order of $1 \mathrm{~km}$ ) and sampled particles displaced from the trap by distances on the order of $10 \mathrm{~km}$. Using remotely sensed surface chlorophyll and a submesoscale-resolving dynamical model, Calil and Richards (2010) make the point that much of the variability in phytoplankton production occurs on short spatiotemporal scales in response to locally intensified upwelling of nutrients. The high-resolution biogeochemical and ${ }^{234}$ Th export model introduced by Resplandy et al. (2012) illustrates that small-scale variability in production is preserved in export flux patterns, perhaps explaining some of the unpredictability in short, upper-ocean, sediment trap-based export observations.

Particle flux measurements that can be made at high time resolution, over long deployments, and without ship support will allow for a great deal of progress in filling the observational gaps discussed above. Bishop et al. (2004) first made such observations in conjunction with a Southern Ocean iron fertilization experiment by using a vertically oriented transmissometer on a neutrally buoyant, drifting float as an "optical sediment trap". Over an $8 \mathrm{~h}$ period, particles accumulating on the upward-facing window of the transmissometer caused an increase in the apparent $c_{\mathrm{p}}(650)$ signal, and Bishop et al. (2004) suggested that the rate of this increase was related to the magnitude of particle flux to the float's drift depth. Indeed, floats deployed inside and outside of the iron-fertilized "patch" exhibited significantly different "carbon flux index" signals (Bishop et al., 2004).

In the oligotrophic ocean, beam attenuation at $650 \mathrm{~nm}$ $\left(c_{\mathrm{p}}(650)\right)$ is routinely used as a proxy for particulate organic carbon (POC) concentration (and less frequently, for mass concentration) because the relationship between the two quantities is an intrinsic property of the suspended particle population (Bishop, 1999; Cetinić et al., 2012; Gardner et al., 2006). However, this general relationship depends on particle size, composition, and degree of aggregation, and it varies regionally and temporally although this variability is constrained (Boss et al., 2009b; Gardner et al., 2006). We expect a similar relationship between POC and $c_{\mathrm{p}}(650)$ to exist for sinking particles, although when we use the transmissometer as an "optical sediment trap", the accumulated particles are compressed into a thin layer rather than being suspended throughout the sampling volume. Since we do not yet have measurements of the POC : $c_{\mathrm{p}}(650)$ relationship for sinking particles, we retain here the directly measured opti- cal units for particle flux (i.e., $\mathrm{m}^{-1} \mathrm{~d}^{-1}$ ), but discuss below the requirements for calibration into carbon flux units.

In the present study, we revisit the method introduced by Bishop (2004) to give a quantitative proxy for particle flux in oligotrophic environments, discussing in detail the associated physical and particle dynamics assumptions. We describe our analysis method, which is amenable to automation and to use with large datasets, and finally present a new, high-resolution particle flux proxy dataset collected over several months in the Sargasso Sea, south of Hawaii, and in the subtropical North Pacific. We use these data to examine variability of particle flux over short spatiotemporal scales and to illustrate the complexity of connections to overlying watercolumn processes.

\section{Methods}

\subsection{Equipment, sampling design, and deployment regions}

The float platform used in this study was the APEX profiler (Teledyne-Webb, Inc.), interfaced to a package of optical sensors ("Bio-Optical Sensor Suite (BOSS)", WETLabs, Inc., and Satlantic, Inc.). Standard APEX sensors included a CTD (SBE41-CP, SeaBird), a dissolved oxygen optode (model 4330, Aanderaa), and a GPS. Two-way Iridium communications facilitated data transmission and real-time sampling plan adjustments. This study uses data collected by five floats with two different sets of sensors. The optical packages on all of the floats included a $700 \mathrm{~nm}$ backscattering sensor, chlorophyll and CDOM fluorometers (ECO Puck, WETLabs, Inc.), $650 \mathrm{~nm}$ beam transmissometer (C-Rover, WETLabs, Inc.), and a four-channel downwelling radiometer (OCR-504, Satlantic, Inc.). Four of the floats (H1-SS4; Table 1) were also equipped with 412 and $440 \mathrm{~nm}$ backscattering sensors (ECO Puck, WETLabs, Inc.) and an upwelling radiometer (OCR-504, Satlantic, Inc.). One float (\#5; Table 1) included a SeaPoint turbidity meter. Only data from the CTD, beam attenuation, $700 \mathrm{~nm}$ backscattering, and chlorophyll fluorescence sensors are discussed further in the present study. In addition to the radiometers and bio-optical sensors, the BOSS units include ancillary tilt and heading sensors.

Floats used in this study followed a shorter variant of the typical Argo profile cycle (www.argo.ucsd.edu). In the first phase of each cycle, floats descended to the programmed drift depth and remained at that depth for a user-determined period of time. Hourly particle flux measurements were made during the drift phase as particles accumulated on the upwardlooking transmissometer window. In order to minimize the amount of vertical motion of the float relative to the surrounding water mass during the drift phase, the standard APEX firmware was updated to reduce the number of active buoyancy adjustments by the float during drift. In this configuration, the floats make buoyancy adjustments only if 
Table 1. Float deployment parameters.

\begin{tabular}{|c|c|c|c|c|}
\hline $\begin{array}{l}\text { Float } \\
\text { number }\end{array}$ & $\begin{array}{l}\text { Primary } \\
\text { operating } \\
\text { region }\end{array}$ & Operation dates & $\begin{array}{l}\text { Cycle } \\
\text { period } \\
\text { (days) }\end{array}$ & $\begin{array}{l}\text { Drift depth } \\
\text { (m) }\end{array}$ \\
\hline $\mathrm{H} 1$ & $\begin{array}{l}\text { Hawaii, subtropical } \\
\text { N. Pacific }\end{array}$ & $\begin{array}{l}17 \text { December } 2011 \\
\text { to present (offshore } \\
\text { since } 10 \text { April 2012) }\end{array}$ & $1-2$ & 1000 (when offshore) \\
\hline $\mathrm{H} 2$ & $\begin{array}{l}\text { South and west of } \\
\text { the Hawaiian islands }\end{array}$ & $\begin{array}{l}18 \text { December } 2011 \\
\text { to present (offshore } \\
\text { since } 15 \text { March 2012) }\end{array}$ & $1-2$ & 1000 (when offshore) \\
\hline SS3 & Western Sargasso Sea & $\begin{array}{l}3 \text { May } 2012 \\
\text { to present }\end{array}$ & $1-2$ & $\begin{array}{l}1000 \text { (except prior to } 11 \text { May, } \\
\text { and } 1 \text { to } 9 \text { June) }\end{array}$ \\
\hline SS4 & Western Sargasso Sea & $\begin{array}{l}03 \text { May } 2012 \text { to } \\
14 \text { November } 2012\end{array}$ & $1-2$ & 1000 (except prior to $12 \mathrm{May}$ ) \\
\hline B5 & BATS vicinity & $\begin{array}{l}12 \text { July } 2012 \text { to } \\
11 \text { August } 2012\end{array}$ & 1 & $150,300,1000$ cycle \\
\hline
\end{tabular}

their measured pressures differ from the target pressure by more than $30 \mathrm{~m}$ for three consecutive hours. On a subset of floats used here, firmware bugs prevented the hourly collection of drift-phase pressure data, although active buoyancy adjustments were unaffected. In these cases, accurate pressure measurements were recorded only at the last point of the drift phase. At the expiration of the drift phase, floats profiled upward through the water column. Water column measurements were collected during ascent, but not descent. Floats always made drift-phase optical measurements in "burst" mode (five rapid observations per "burst"). Early in each mission, all burst observations were transmitted, but after characterization of measurement variability was complete, only the burst medians were transmitted in order to minimize data volume. Upon surfacing after each profile cycle, the floats acquired a GPS fix, telemetered data over Iridium to a landbased server, and received updated instructions, if any, for the next cycle. Duration of vertical profile phases varied with the drift depth, lasting approximately $4 \mathrm{~h}$ for $1000 \mathrm{~m}$ drift depths and $1 \mathrm{~h}$ for $150 \mathrm{~m}$ drift depths.

General mission details are given in Table 1, and general sampling regions and time frames are shown in Fig. 1. The primary mission of float B5 was to collect subeuphotic zone particle flux data near the Bermuda Atlantic Time-series Study (BATS) site. It was thus directed to drift for 1-day periods, cycling among depths of 150,300 , and $1000 \mathrm{~m}$, over the deployment period of approximately 1 month. Collection of particle flux data was not the primary mission of floats $\mathrm{H} 1-$ SS4, so they drifted primarily at $1000 \mathrm{~m}$ and profiled every 1 or 2 days. At the time of writing, $\mathrm{H} 1$ and $\mathrm{H} 2$ have been in operation for over a year and collected over 200 profiles; only data collected prior to November 2012 are presented here.

\subsection{Water column data analysis}

After downloading and unpacking the binary data telemetered by the float, data processing consisted of the application of calibration constants and pressure/time alignment of raw data from the various sensors, followed by a series of postprocessing steps including computation of the particle flux proxy from relative $c_{\mathrm{p}}(650)$ data collected during the drift phase. Each sampling event lasted between 10 and approximately $70 \mathrm{~s}$, depending on the number of independent parameters being measured. Raw data from each sensor were first aligned according to time stamp, and pressures were interpolated onto each instrument's time axis using the pressures and times measured by the CTD. These pressures were adjusted according to each sensor's vertical offset from the pressure sensor. Very rarely, raw bio-optical data corresponded to nonphysical values (negative or above maximum instrument response). These were removed from the dataset.

Predeployment calibrations were applied to the $700 \mathrm{~nm}$ backscattering $\left(b_{\mathrm{b}}(700)\right), c_{\mathrm{p}}(650)$, and chlorophyll fluorescence data. Volume scattering at $700 \mathrm{~nm}\left(\beta\left(140^{\circ}, 700\right)\right.$, $\left.\left[\mathrm{m}^{-1} \mathrm{sr}^{-1}\right]\right)$ was derived from raw backscatter sensor output using the calibration slope provided by the manufacturer and a dark sensor reading measured in water aboard the float during ballasting tests. Volume scattering by seawater (computed from interpolated temperature and salinity measurements, Zhang et al., 2009) was removed, and calibrated $\beta\left(140^{\circ}, 700\right)$ data were transformed to particulate backscattering coefficients $\left(b_{\mathrm{bp}}(700),\left[\mathrm{m}^{-1}\right]\right.$; Boss and Pegau, 2001). Raw C-Rover signals equivalent to $<50 \%$ light transmission (near end of life for float SS4; see Sect. 2.3, below) were removed from further analysis. Predeployment clean-water values provided by the manufacturer were used to convert raw $\mathrm{C}$-Rover readings to relative $c_{\mathrm{p}}(650)$ values. The sensor manufacturer's factory calibration slope and a dark offset derived from deep-water values (see below) were applied 

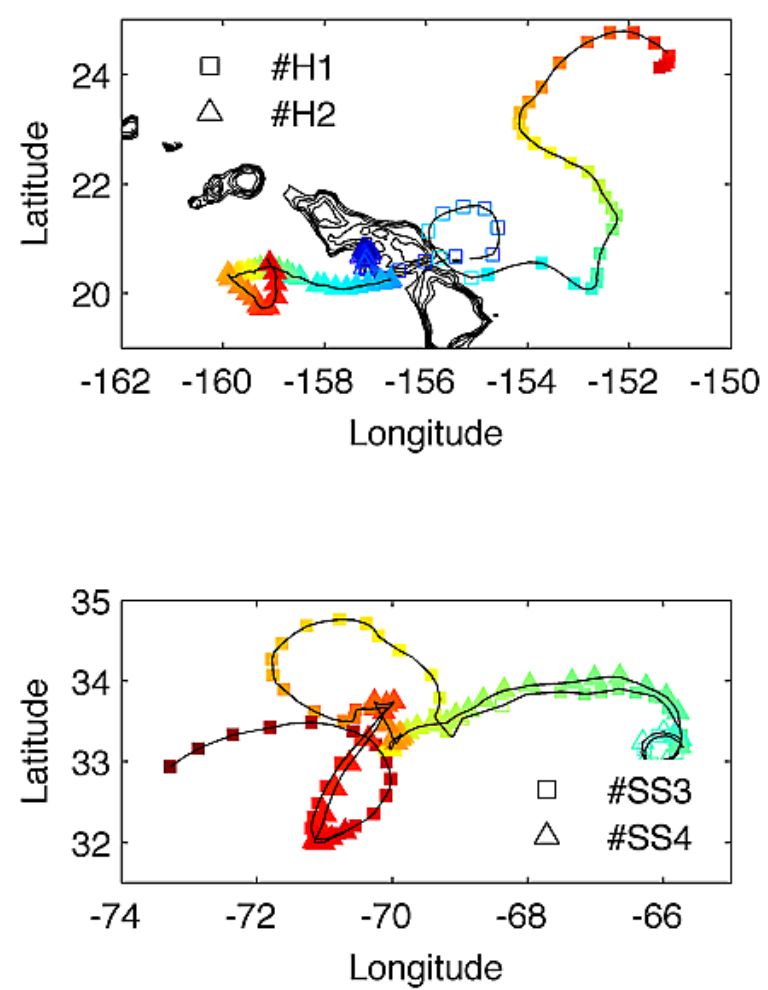

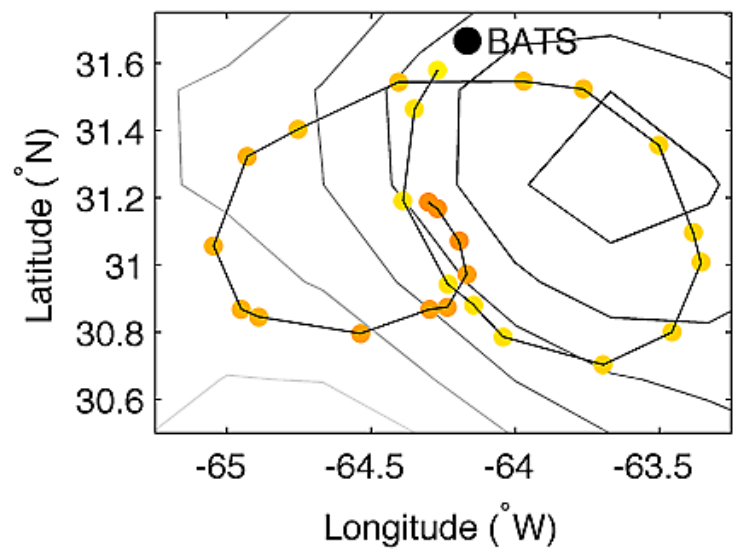

12-17-11 03-16-12 06-14-12 09-12-12

Fig. 1. Float paths and sampling dates. Deployment parameters are summarized in Table 1. Time color scale applies to all panels. Upper left: floats H1-H2 near Hawaii. Every 3rd surfacing location shown for clarity. Depth contours are shown every $500 \mathrm{~m}$ from $2000 \mathrm{~m}$ to the surface; open symbols denote profiles in water $<2000 \mathrm{~m}$ deep or profiles to shallower than $1000 \mathrm{~m}$. Lower left: floats SS3-SS4 in the western Sargasso Sea, symbols as in upper panel. Every other surfacing location is shown. Upper right: float B5 in the vicinity of the BATS site. The float was deployed at BATS (black circle) and moved counterclockwise along its path. SSH contour spacing is $5 \mathrm{~cm}$; contours show location of cyclonic mesoscale eddy on 8 July 2012, the week prior to deployment (data: AVISO).

to the chlorophyll fluorescence data to give the fluorometric chlorophyll concentration $\left(F_{\mathrm{chl}},\left[\mu \mathrm{g}-\mathrm{Chl} \mathrm{L}^{-1}\right]\right)$ although the extracted Thalassiosira weissflogii standard used for the calibration was likely not representative of any of the float deployment regions. At present, we interpret water-column $F_{\text {chl }}$ values in a relative sense only, since discrete samples against which to calibrate the sensors were not collected during initial deployments of all floats.

Smoothed profiles of $F_{\mathrm{chl}}, b_{\mathrm{bp}}(700)$, and $c_{\mathrm{p}}(650)$ were derived following the method detailed by Briggs et al. (2011). Briefly, profiles were subjected to a 7-point running minimum followed by a 7-point running maximum filter to separate spikes from the baseline. While spikes in water-column bio-optical properties have been related to abundances of large particles and zooplankton (Bishop and Wood, 2008; Briggs et al., 2011; Gardner et al., 2006), sampling rates were generally too low here to generate statistically meaningful spike counts, so only baseline data are discussed below.

\subsection{Sensor drift and compensation strategies}

Bio-optical sensors used in long-term deployments are subject to drift, which can have a number of causes including biological fouling. A typical compensation strategy is to remove any long-term trend in deep-water sensor values (e.g., Gardner et al., 2006). The assumption is that biological particles in the water column are rare enough in deep water that long-term changes can be attributed to sensor drift (which could include long-term buildup of organic matter on the sensor). Water-column minima in $F_{\mathrm{chl}}, b_{\mathrm{b}}(700)$, and $c_{\mathrm{p}}(650)$ (Fig. 2) were determined over time for all floats (Table 1) by taking the median of the five lowest observations in each profile (excluding profiles shallower than $900 \mathrm{~m}$ ). Neither $F_{\text {chl }}$ nor $b_{\mathrm{b}}(700)$ sensors experienced large drifts (Fig. 2). Deep values of $b_{\mathrm{bp}}(700)$ were not subtracted from profiles because they may have resulted from real environmental variability in deep-water particulate matter. Since deep-water chlorophyll fluorescence can reasonably be assumed to equal zero, $F_{\text {chl }}$ profiles were adjusted by subtracting a constant offset to make the minimum $F_{\text {chl }}$ value equal to zero. The $F_{\text {chl }}$ minimum often occurred around $300-600 \mathrm{~m}$, possibly due to 

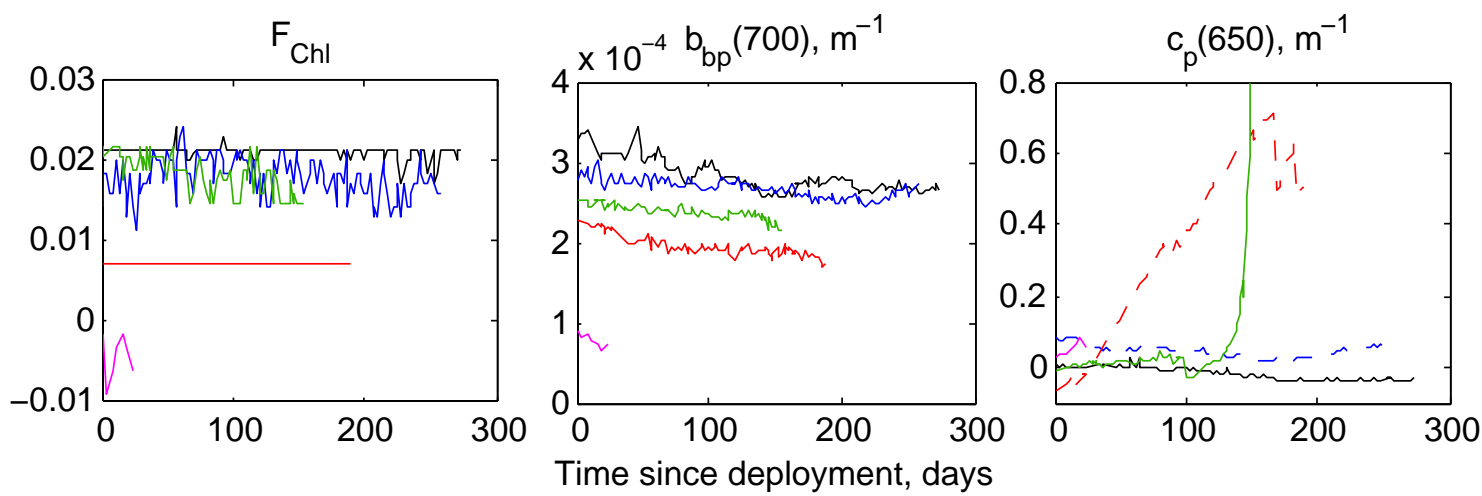

$-\mathrm{H} 1 \longrightarrow \mathrm{H} 2 \longrightarrow \mathrm{SS} 3 \stackrel{\mathrm{BS}}{-\mathrm{B} 5}$

Fig. 2. Long-term changes in deep-water values for sensors on each of the five floats. Left panel: chlorophyll fluorescence. Offsets among floats are primarily due to imperfect calibration and are close to detection limits. Middle panel: $b_{\mathrm{bp}}(700)$. Offsets among floats are likely due both to small differences in initial calibration coefficients and to differences in deep particle concentrations. Right panel: $c_{\mathrm{p}}(650)$. Dashed lines show floats with "rinsing hose" configuration (see text); solid lines without. Initial differences are due to instrument calibration and variability in deep attenuation values; subsequent drift is likely due to biological fouling (float SS3-SS4) and/or changes in deep-water attenuation (floats $\mathrm{H} 1-\mathrm{H} 2$ ).

signal contamination in deeper water by fluorescence of dissolved organic matter (FDOM; Proctor and Roesler, 2010), whose concentration increased with depth (not shown).

In this study we used $c_{\mathrm{p}}(650)$ data only in a relative sense (rate of change during each drift phase), so adjustment for long-term sensor changes was not required. However, we tracked long-term deep-water values (Fig. 2) in order to investigate effectiveness of optical-window clearance methods. Floats $\mathrm{H} 2$ and SS3 were configured with hoses directing the outflow from the pumped CTD conductivity cell to rinse off the upward-facing transmissometer window at the end of each drift phase, similar to the setup of Bishop et al. (2004) and Bishop and Wood (2008); all other floats' windows were cleared passively by the upward motion of the floats at the beginning of each upward profile. Deep minimum $c_{\mathrm{p}}(650)$ values from floats $\mathrm{H} 1$ and $\mathrm{H} 2$, deployed in the subtropical North Pacific, were stable and qualitatively seemed to parallel deep $b_{\mathrm{bp}}$ (700) values (Fig. 2). On the other hand, and unlike corresponding chlorophyll and backscattering sensors, transmissometers on two Atlantic floats (SS3-SS4) exhibited changes consistent with biological fouling (Fig. 2). Interestingly, float SS4 (no hose) reported more stable deep $c_{\mathrm{p}}(650)$ values than float SS3 (with hose) for months, but then fouled quite rapidly over the course of just a few days (Fig. 2) and stopped communicating shortly afterwards. Whether fouling on float SS4 could have been prevented with the hose configuration is unclear.

Hose presence or absence made little difference in the time necessary to clear the window upon ascent. We defined this as reaching the water-column minimum $c_{\mathrm{p}}(650)$ value for that profile, assuming that in most cases $c_{\mathrm{p}}(650)$ should monotonically decrease with increasing depth. The first $100 \mathrm{~m}$ of ascent were sufficient to clear the window 96 and $98 \%$ of the time for Pacific floats $\mathrm{H} 1$ and $\mathrm{H} 2$, and 89 and $75 \%$ of the time for Atlantic floats SS3 and SS4. The ascent distance necessary to clear the window $99 \%$ of the time was $225 \mathrm{~m}$ for Pacific floats and $520 \mathrm{~m}$ for Atlantic floats; float B5 was consistently clear after $20 \mathrm{~m}$ ascent, but was only deployed for a month. In spite of large and variable offsets in $c_{\mathrm{p}}(650)$, transmissometers on all floats continued to provide well-resolved relative measurements through most of their lives, allowing for their use as "optical sediment traps".

\subsection{Derivation of flux proxy}

We describe the procedure used to derive the particle flux proxy with reference to the example shown in Fig. 3. First, we removed drift-phase data points collected prior to the float reaching its target depth (or during the first $2 \mathrm{~h}$, if pressure data were not recorded). If fewer than eight driftphase $c_{\mathrm{p}}(650)$ observations remained, the flux proxy was not computed. The $c_{\mathrm{p}}(650)$ signal usually increased steadily for hours at a time, but these periods were sometimes punctuated by "spikes" (defined as an increase in $c_{\mathrm{p}}(650)$ followed by a decrease within $3 \mathrm{~h}$ ) and "jumps" (persistent, discontinuous increases or decreases; Fig. 3). Spikes (threshold $=0.072 \mathrm{~m}^{-1} \mathrm{~d}^{-1}$ ) were removed from further analysis, while jumps (downward threshold $=-0.062 \mathrm{~m}^{-1} \mathrm{~d}^{-1}$; upward threshold was dynamic) were used to divide $c_{\mathrm{p}}(650)$ vs. time data into "segments". Thresholds were chosen initially to correspond to twice the standard deviation of the instrument noise $\left(0.0013 \mathrm{~m}^{-1}\right)$ per hour. During low-flux drift phases, this tended to flag as "spikes" data points that 
qualitatively seemed due to instrument noise, so we increased the spike threshold to $0.072 \mathrm{~m}^{-1} \mathrm{~d}^{-1}$.

For each segment, the slope and intercept were determined via linear regression, along with the $R^{2}$ value and the rootmean-squared error (RMSE) of the fit (Fig. 3). Segments with negative slopes, which occurred less than $10 \%$ of the time (except near end of life for float SS4), were removed from further analysis. RMSE and $R^{2}$ values of remaining segments were tested for goodness of fit and segment linearity $\left(R_{\text {thres }}^{2}>0.5 ; \mathrm{RMSE}_{\text {thres }}>0.0125 /\left(N_{\mathrm{obs}}-2\right)^{1 / 2}\right.$, where $N_{\text {obs }}$ is the total number of drift-phase observations, allowing for $\mathrm{RMSE}_{\text {thres }}$ to decrease for longer drift phases). Segments not meeting these criteria were subdivided at the largest hourly differential $c_{\mathrm{p}}(650)$ value, creating a new "jump" and two new segments. The process was repeated until all segments either met the fitting criteria or were eliminated based on length, with no flux estimate made (at least four observations required). The $R^{2}$ criterion was meant to ensure subdivision of non-linear segments, but also had the potential to eliminate low-flux segments (good RMSE values but slopes near zero). However, an examination of the data showed that occurrences of such segments were negligible.

While we interpret steady, upward-trending periods as the slow accumulation of settling particles on the transmissometer window (following Bishop et al., 2004), spikes and downward jumps are unlikely to be due to particle flux. We hypothesize that spikes could be due to transient particles passing through the transmissometer sampling volume without landing on the window, or perhaps even encounters with active swimmers, which are known to occur in sediment traps (Karl and Knauer, 1989; Knauer et al., 1979; Lee et al., 1988) and which have been captured via in situ photography (Bishop, 2009). Sometimes these spikes had large intra-burst variability (Fig. 3), but this was not always the case. By contrast, we must consider more strongly the possibility that upward jumps represent real particle flux events. Below, we refer to the steadily increasing part of the drift-phase $c_{\mathrm{p}}(650)$ as the "continuous" component of the flux proxy, and upward jumps as the "discontinuous" component.

The continuous flux proxy was computed by averaging the slopes of length-weighted segments into 1-, 3-, and 14day time bins (we compare the latter two averaging periods to sediment trap time series data, below). The discontinuous flux proxy was computed for each drift phase by dividing the total $c_{\mathrm{p}}(650)$ increase from upward jumps by the total length of continuous segments during the corresponding drift phase. The discontinuous flux proxy was likewise binned into 1-, 3and 14-day time intervals. For floats H1-SS4 (Table 1), we computed mean, standard deviation, and median fluxes for the 1-day-averaged time series. Empirical, cumulative probability distributions were also derived from continuous and total (discontinuous + continuous) flux time series after binaveraging to 1 day. As a measure of the importance of highflux events, we computed the fractional contribution of the upper $10 \%$ of 1-day flux observations to total flux observed

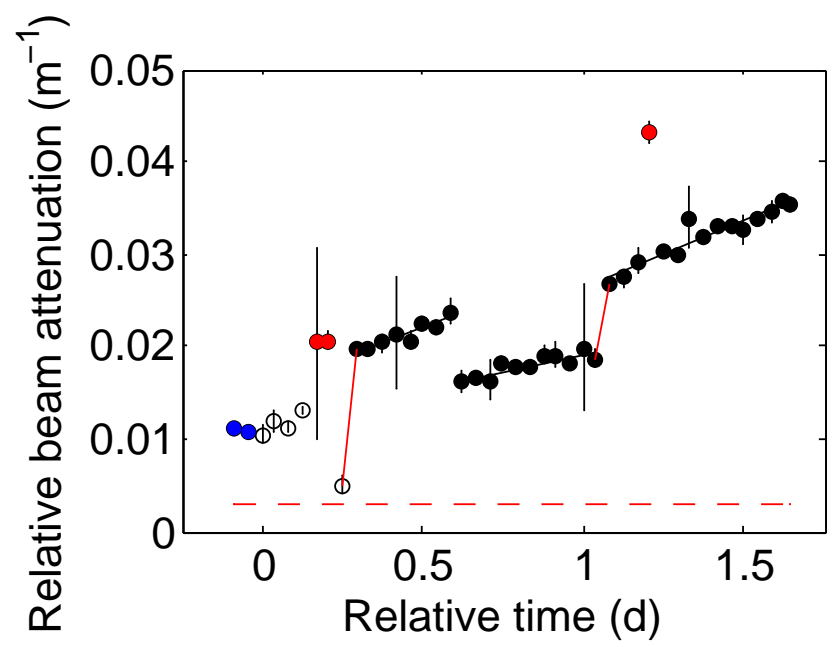

Fig. 3. Example of flux proxy determination, chosen because all pertinent features are represented. All points show drift-phase $c_{\mathrm{p}}(650)$ observations, each the median of a 5-point "burst". Vertical black lines show $\pm 70 \%$ interval within each burst (most are hidden beneath symbols). Red circles show "spikes" not used in flux determination. The first two points (solid blue) were excluded to allow for float to reach target depth; points marked with open circles did not satisfy goodness-of-fit criteria; see text. Filled black circles show points used for linear fitting of continuous flux component. Fitted segments (black lines) had relative slope uncertainties of 36, 45 , and $21 \%$. Positive jumps (solid red lines) were summed and normalized to the drift-phase length (dashed red line) to estimate the discontinuous flux component.

by floats H1-SS4. Finally, to describe the relative variability of flux observations, we computed the coefficient of variation $(\mathrm{CV}$; ratio of standard deviation to the mean) of logtransformed data after averaging to 3- and 14-day periods (see Sect. 3.1, below). We also report the $95 \%$ confidence interval of the $\mathrm{CV}$ (propagated from fitting uncertainty to a lognormal distribution; Matlab ${ }^{\circledR}$ function lognfit.m).

\section{Results and discussion}

\subsection{Variability in $1000 \mathrm{~m}$ particle flux}

Flux proxy data from floats H1-SS4 (Fig. 4) allow for us to examine, for the first time, the statistical variability of particle flux at near-daily time resolution over periods of months (Table 2). Statistical descriptors presented in Table 2 were computed from 1-day-binned observations made at $1000 \mathrm{~m}$ and in waters deeper than $2000 \mathrm{~m}$. To avoid gaps longer than 1-2 days, we limited analysis of data from floats H1 and SS3 to periods after their final shallow profile cycles (Fig. 1, Table 1). By excluding shallow and near-land data, we also seasonally limited the analysis to the postbloom, prewinter mixing period. Without bin averaging, continuous flux proxy segments (Fig. 4, odd panels) illustrate the variability 

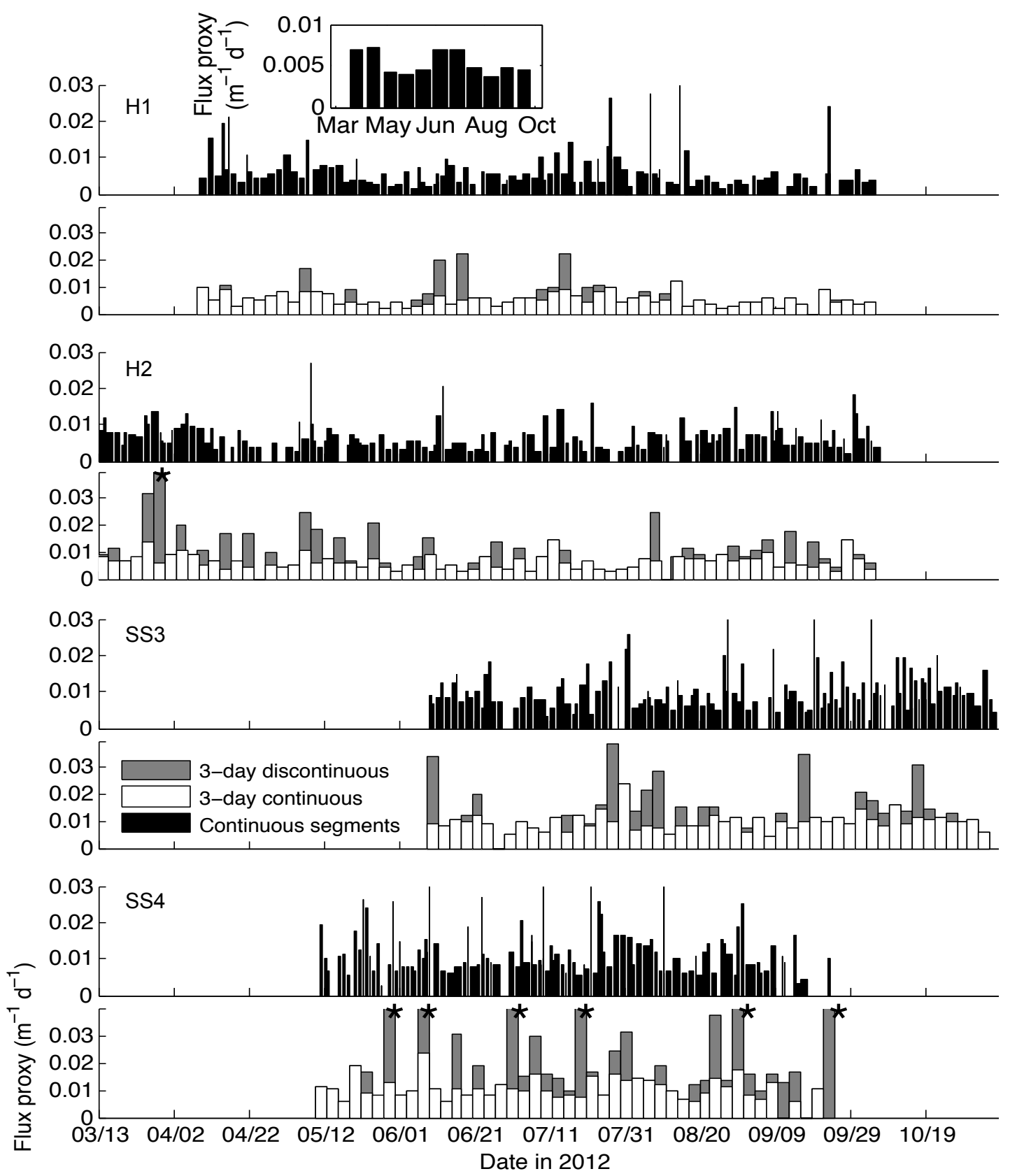

Fig. 4. Flux proxy time series for floats H1-SS4 (Table 1). Only flux data measured at $1000 \mathrm{~m}$ depth and at least $1000 \mathrm{~m}$ above the bottom are shown. Top panel in each pair shows flux as determined from individual segment fits (black; continuous component of flux proxy only). Bottom panel in each pair shows 3-day, bin-averaged flux from both continuous (white) and discontinuous (gray) components. Bar heights show flux magnitude; width shows time span. Bars marked with asterisks are off-scale. Note scale difference between upper and lower panel in each pair. Inset in rescaled, upper panel shows float H1 flux bin-averaged to 17 days (see text).

of particle flux over short time intervals, even at $1000 \mathrm{~m}$. Unsurprisingly, 3-day, bin-averaged, continuous flux proxy data contained less variability (Fig. 4, even panels, gray bars) although the corresponding discontinuous flux component (Fig. 4, even panels, white bars) remained quite variable. Seasonal variability was not strongly evident in datasets from floats H2, SS3, and SS4, although float H1 observed broad flux maxima in April and July, consistent with the seasonality of carbon fluxes in deep traps at station ALOHA north of Hawaii (data averaged to 17-day trap period, Fig. 4 inset; Karl et al., 2012). Variability on temporal scales of weeks, corresponding to mesoscale spatial distances of tens of kilometers (Fig. 1), was visible in the 3-day-averaged continuous flux component data (Fig. 4). The two subtropical North 
Table 2. 1-day-binned flux proxy time series statistics for floats H1, H2, SS3, and SS4.

\begin{tabular}{lllll}
\hline Float & $\begin{array}{l}\text { Mean (standard } \\
\text { deviation) } \\
1000 \mathrm{~m} \text { flux } \\
\left(\mathrm{m}^{-1} \mathrm{~d}^{-1}\right)\end{array}$ & $\begin{array}{l}\text { Median } \\
1000 \mathrm{~m} \\
\text { flux } \\
\left(\mathrm{m}^{-1} \mathrm{~d}^{-1}\right)\end{array}$ & $\begin{array}{l}\text { Percentage of } \\
\text { total flux from } \\
\text { top 10\% of obs. } \\
\text { (cont. only) }\end{array}$ & $\begin{array}{l}\text { Percentage of } \\
\text { total flux from } \\
\text { top 10\% of obs. } \\
\text { (discont. + cont.) }\end{array}$ \\
\hline H1 & $0.006(0.004)$ & 0.005 & $23 \%$ & $28 \%$ \\
H2 & $0.006(0.003)$ & 0.006 & $19 \%$ & $30 \%$ \\
SS3 & $0.010(0.005)$ & 0.009 & $19 \%$ & $24 \%$ \\
SS4 & $0.011(0.005)$ & 0.010 & $18 \%$ & $51 \%$ \\
\hline
\end{tabular}

Pacific floats observed lower mean and median particle fluxes than the two Sargasso Sea floats (Table 2, Fig. 5). This relationship is consistent with deep sediment trap observations from these regions of the ocean (Honjo et al., 2008). All floats recorded disproportionate contributions of high-flux events to time-integrated totals, with the top $10 \%$ of continuous flux observations contributing $18-23 \%$ of the total flux (Fig. 6). Inclusion of the discontinuous component increased mean flux values by $27-143 \%$, and increased the contribution of the top $10 \%$ of observations to $24-51 \%$ (Table 2).

As suggested by the importance of high-flux events and by visual observation (Fig. 5), 1-day-averaged fluxes observed by the floats were lognormally distributed (Lilliefors test, $95 \%$ confidence interval). Below, we compare the shape of these distributions and the relative variability within flux proxy data records to direct measurements from sediment trap time series in the Sargasso Sea and subtropical North Pacific. This provides a qualitative validation of the proxy method and gives some insight into issues of undersampling by periodic time series observations.

The sediment trap data from the BATS, Oceanic Flux Program (OFP), and Hawaii Ocean Time-series (HOT) programs provide independent records of carbon flux variability in the oligotrophic ocean (Conte et al., 2001; Karl and Lukas, 1996; Steinberg et al., 2001). The drifting, BATS and HOT sediment trap arrays are deployed respectively at 150, 200, and $300 \mathrm{~m}$, and 150,300 , and $500 \mathrm{~m}$ for approximately 3 days each month, while the moored OFP traps are deployed at 500,1500 , and $3200 \mathrm{~m}$, and currently collect continuously with a 14-day sampling interval (Conte et al., 2001; Karl et al., 1990; Steinberg et al., 2001). Sampling methods are described extensively elsewhere (Conte et al., 2001; Karl et al., 1990; Knap et al., 1997). We downloaded all available $300 \mathrm{~m}$ POC flux data from the BATS website (bats.bios.edu), $500 \mathrm{~m}$ carbon flux data from the HOT website (hahana.soest.hawaii. edu/hots), and obtained $1500 \mathrm{~m}$ OFP POC flux data from the data appendix to Conte et al. (2001). Because floats did not profile to $1000 \mathrm{~m}$ in deep water over a full annual cycle, we only used trap data corresponding to times of year when float data were collected (Fig. 1, Table 1). We also discarded the first few years of OFP data, which had 2-month sample collection periods, as well as years where the $1500 \mathrm{~m}$ trap was

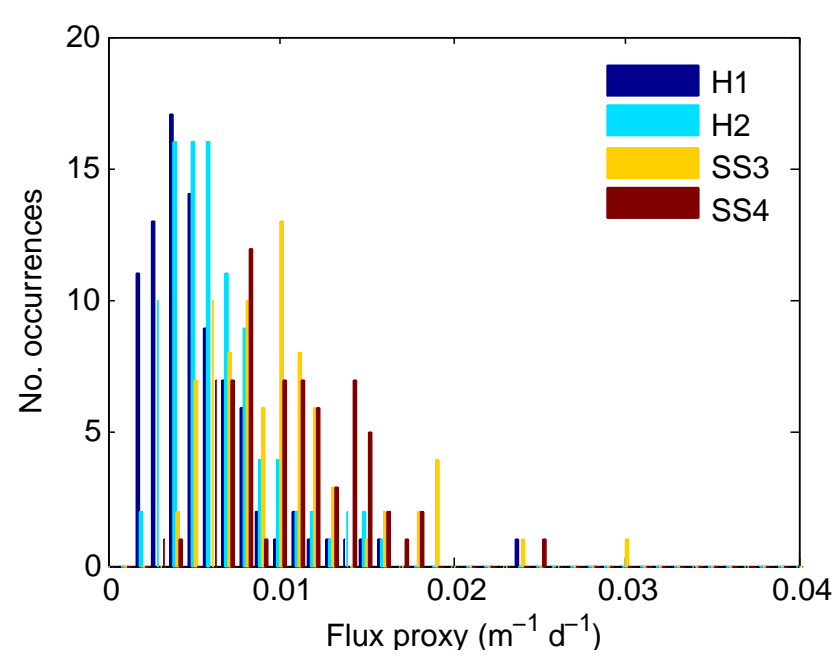

Fig. 5. Histogram of continuous flux proxy data from floats H1-SS4 (Table 1). Data were bin-averaged to 1 day.

fitted with a zooplankton-exclusion screen that may have reduced fluxes (see Conte et al., 2001). Thus filtered, $21 \mathrm{yr}$ of BATS data, 6 yr of HOT data, and 4 yr of OFP data remained.

Like the 1-day-averaged float data, the BATS $300 \mathrm{~m}$ POC and HOT $500 \mathrm{~m}$ carbon flux data were lognormally distributed (Lilliefors test, $95 \%$ confidence interval). The same could not be established with confidence for the $1500 \mathrm{~m}$ OFP fluxes and the 3- and 14-day-averaged float datasets because of smaller sample numbers, but qualitative examination also suggested a lognormal distribution. For trap time series, we computed CV values from log-transformed flux data, as well as the mean and standard deviation of annual $\mathrm{CV}$ values from all data years.

The mean CVs of all three trap time series were nearly identical, although the BATS and OFP trap time series had greater interannual variability than at HOTS (Fig. 7). Within the two deployment regions, CVs of continuous flux proxy data also agreed well among floats and 3-dayaveraged trap time series. The correspondence between 3day-averaged float data (originally observed at higher time resolution) and BATS and HOT records suggests that in a time-integrated sense, the 3-day, monthly sampling periods 


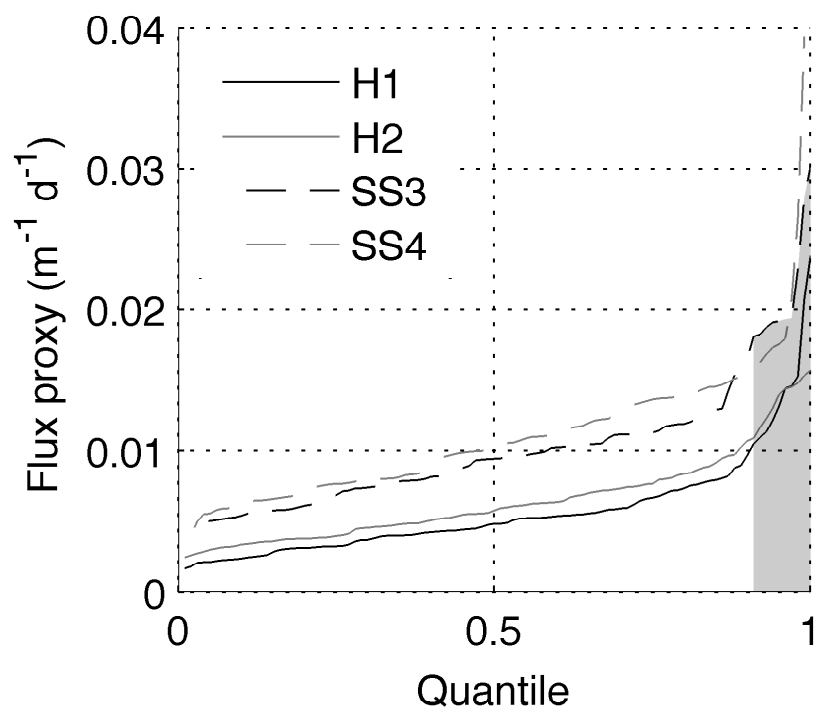

Fig. 6. Cumulative distribution plot of 1 day, bin-averaged, continuous flux proxy data from floats H1-SS4. Solid lines show Pacific floats, and dashed lines Atlantic floats. Gray-shaded area illustrates the contribution of the top $10 \%$ (90th-100th percentile range) of 1-day flux averages observed by float SS3.

of those programs are sufficient to capture extreme-flux events (consistent with the analysis of Michaels et al., 1994). Averaged to 14-day periods, floats SS3-SS4 actually observed slightly less flux variability than was recorded by the OFP trap, but there is some overlap between ranges (Fig. 7), and we cannot rule out interannual variability $(N=4 \mathrm{yr}$ of OFP data, and 1 yr of float data).

\subsection{Discontinuous flux component}

If the discontinuous flux component were caused by large, episodic flux events, then those events should be recorded both by floats and by traditional sediment traps. In other words, we would expect the distribution shapes and CVs of time-averaged flux observations from floats, with the discontinuous component included, to match records from sediment traps. As a test, we summed the discontinuous and continuous flux proxy records from each float and repeated the comparisons made above. Inclusion of the discontinuous flux component added high-flux observations to all records (e.g., Fig. 4), lengthening the upper "tail" of the distribution. Although 1-day-averaged fluxes from floats H1 and SS4 no longer fit a lognormal distribution (Lilliefors test, $95 \%$ confidence), we still computed CVs on log-transformed data for consistency. Unsurprisingly, in all cases the recomputed CVs were larger than for the continuous component alone. Coefficients of variation for floats $\mathrm{H} 1, \mathrm{H} 2$, and SS4 exceeded the corresponding ranges at BATS and HOT, and the CV for float SS4 (after averaging to 14 days) was also high relative to OFP (Fig. 7). Only float SS3 still observed similar relative variability to sediment trap records when the discontinuous component was included.

Evidence presented here cautions against the assumption that episodic particle collection is the sole driver of the discontinuous flux component, and there are several possible alternative causes that we cannot test at present. The prevalence of zooplankton "swimmers" in sediment traps (Karl and Knauer, 1989; Knauer et al., 1979; Lee et al., 1988) and in situ imagery collected by Bishop and Wood (2012; 2009) suggest that these organisms may also be attracted to and interact with (e.g. shift material within, feed from, or defecate on) the transmissometer sampling volume on a drifting float. The same low-energy turbulence that allows for collection of particles by the transmissometer could also occasionally resuspend them. Downward jumps were less frequent than upward jumps, and net magnitudes were a factor of 5 smaller, suggesting that some, but not all, upward jumps were simply due to movement of material on the window $(3.4 \mathrm{~cm}$ diameter) into or out of the sampling beam $(0.76 \mathrm{~cm}$ diameter). A rigorous evaluation of the physical meaning of the discontinuous flux component will require detailed comparisons to simultaneously collected trap samples and particle imagery (Bishop and Wood, 2012; Bishop, 2009). Below, we focus further discussion only on the continuous flux component.

\subsection{Depth-resolved flux time series at BATS}

As described above, float B5 cycled through approximately $24 \mathrm{~h}$ drift phases at 150, 300 and $1000 \mathrm{~m}$ as it spiraled counterclockwise around a westward-propagating cyclonic eddy near the BATS site for approximately 1 month (Fig. 1). Spatiotemporal variability in the particle flux proxy generally decreased with depth (Fig. 8a). Particularly in the latter half of the deployment, measurements at $150 \mathrm{~m}$ even exhibited substantial variability within single drift phases (Fig. 8a). Aligning profile-cycle mean flux measurements from the three depths into 3-day quasi-synoptic "profiles", we see that flux attenuation also displayed substantial variability (Fig. 8d). Between $150 \mathrm{~m}$ and $300 \mathrm{~m}$, it occasionally decreased, or even became negative (27 July to 1 August and 8-10 August, Fig. $8 \mathrm{a}$ and $\mathrm{b}$ ). This is not inconsistent with previous sediment trap measurements at BATS, where $\sim 6 \%$ of monthly observations show higher fluxes at $300 \mathrm{~m}$ than at $150 \mathrm{~m}$ (data available from bats.bios.edu). Possible causes include shorttimescale changes in particle production, the remineralization length scale, the euphotic zone depth and thus the depth of particle production, the degree of active particle transport by zooplankton, and small-scale horizontal gradients in particle flux (Buesseler and Boyd, 2009; Resplandy et al., 2012). The initial high-flux measurement at $1000 \mathrm{~m}$ may reflect heterogeneity in particle export (see below), and if particles were settling rapidly, would be decoupled from shallower observation depths since the float only measured one depth per day. Excluding the initial $1000 \mathrm{~m}$ measurement, the mean Martin curve exponent for the entire deployment was 


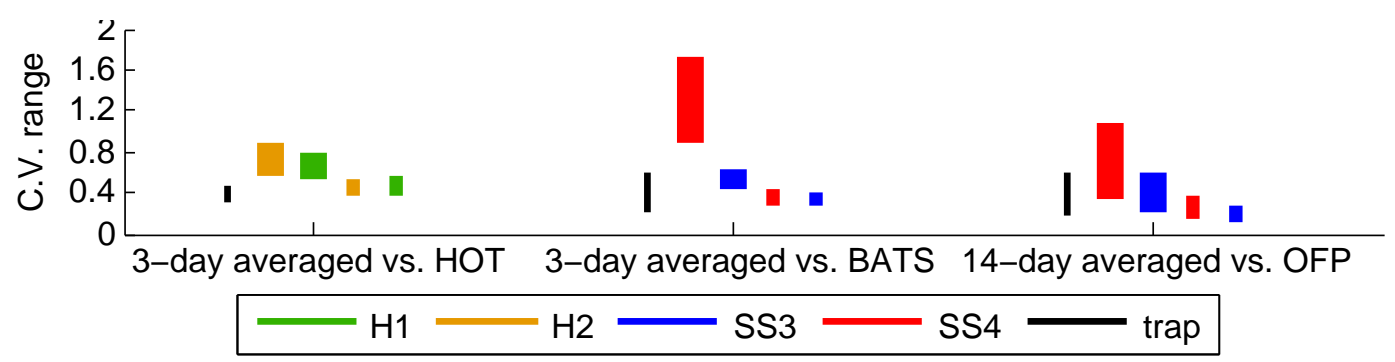

Fig. 7. Coefficient of variation (CV) ranges of log-transformed float and sediment trap time series data. Black lines show annual CV distribution from BATS, HOT, and OFP records. Each colored bar shows the $95 \%$ confidence range for the CV value of observations from floats with (thick bars) and without (thin bars) inclusion of the discontinuous flux component.
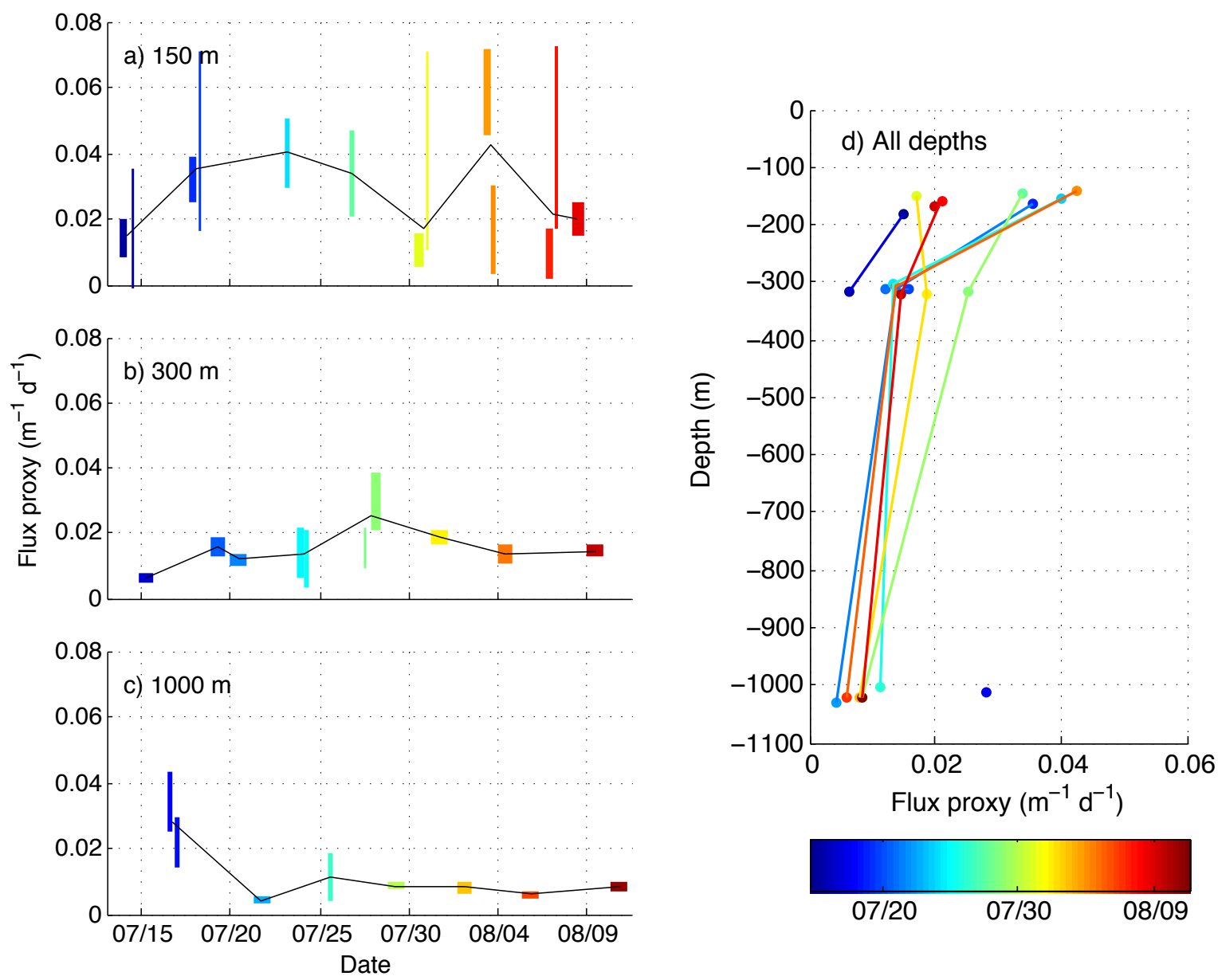

Fig. 8. Depth-resolved flux proxy from float B5. (a-c) Time series of flux measured at 150, 300, and $1000 \mathrm{~m}$. Black lines are drawn through weighted mean flux values for each profile cycle. Colored bars show temporal extent (width) and fitting uncertainty (height) of best-fit segments. (d) Profile-cycle mean flux proxy data organized into 3-day profiles. Color scale corresponds to date and applies to all panels.

-0.86 , consistent with classical trap-based views of particle flux attenuation (Martin et al., 1987), but the $95 \%$ confidence interval on the exponent, $[-1.26,-0.47]$ is almost as large as the entire range predicted by Henson et al. (2012) for the global ocean. This variability illustrates the underlying shortterm complexity of processes controlling flux attenuation.

\subsection{Connections to the overlying water column}

Decoupling between upper-water-column production and deep particle export has been observed before in the oligotrophic regions sampled here (e.g., Buesseler et al., 2009; Karl et al., 2012; Steinberg et al., 2001). Consistent with 
prior studies, no strong temporal relationship exists between float-based $1000 \mathrm{~m}$ flux and upper-water-column bio-optical properties. The two Pacific floats' trajectories (Fig. 1) were offset by about $60^{\circ}$ from the estimated surface geostrophic velocities (derived from AVISO sea level; data not shown), making it unlikely that profiled bio-optical data coincided spatially with source waters of particles simultaneously settling to $1000 \mathrm{~m}$ depth. The Atlantic floats, on the other hand, traveled closer to the same direction as overlying surface currents (offset $10-20^{\circ}$ to the right). Float SS4, in particular, tracked the decaying bio-optical signature of the cyclone in which it was deployed for several weeks (Figs. 1 and 8). The two strongest flux peaks in that float's time series lagged behind upper-water-column "hot spots" in $b_{\mathrm{bp}}(700)$ and $F_{\mathrm{chl}}$, and are consistent with particle settling velocities of $150 \mathrm{~m} \mathrm{~d}^{-1}$ (23 May peak) and $450 \mathrm{~m} \mathrm{~d}^{-1}$ (10 June peak) (Fig. 9). In general, however, particle flux observed at $1000 \mathrm{~m}$ floats H1-SS4 was uncorrelated to the magnitude of observed bio-optical parameters (e.g., $b_{\mathrm{bp}}(700)$ and $\left.F_{\mathrm{chl}}\right)$ in the overlying water column. This is not unexpected when we consider that particles collected by a drifting float at $1000 \mathrm{~m}$ may not have originated along the float's path, and are likely to have settled from regions tens of kilometers distant (Siegel et al., 2008).

\subsection{Flux proxy calibration approach and assumptions}

Although we lack the empirical measurements of sinking particles' $\mathrm{POC}$-to- $c_{\mathrm{p}}(650)$ characteristics that are necessary to calibrate the flux proxy into carbon flux units, we outline the conceptual approach and discuss related assumptions here. We must first assume that settled particles and any fouling material on the transmissometer window do not interact optically or introduce multiple scattering effects (note that this is not the same as geometric overlap, since particles also diffract light around their edges). Justifying this assumption, we generally observed $c_{\mathrm{p}}(650)$ to increase steadily for hours (Fig. 3) and sometimes for entire 1-2-day drift phases, rather than the rate slowing with increasing $c_{\mathrm{p}}(650)$ as would be expected if multiple scattering were increasing the light path through the particle layer at high $c_{\mathrm{p}}(650)$ values.

Second, we must account for two forms of shading of particle flux to the transmissometer window: (1) from the sides by the adjacent float body and by the support struts connecting the upper and lower parts of the transmissometer, and (2) from directly above by the upper part of the transmissometer (Fig. 10). We made a simplified estimate of shading from the sides by using the relative instrument dimensions to determine the angular fraction of the window circumference that is occluded by the float and by the support struts. Approximately $21 \%$ of the circumference is blocked by the float body and $29 \%$ by the four support struts (with $3 \%$ overlap, see Fig. 10), so we assumed that particle flux to the window is reduced by approximately $47 \%$.
Estimating shading from above is more complex. Neutrally buoyant floats are advected with the mean current but still experience turbulence on spatial scales smaller than their own size, and we hypothesize that these small motions allow for particles to accumulate on the transmissometer window even though it is shaded from directly above (analogous to standing under a very tall, narrow umbrella in gently swirling snow). In this case, overhead shading will depend on the local turbulence at scales smaller than the float, and will affect slowest-settling particles the least. Random motions will be very likely to advect slowly settling particles horizontally over the window (instrument radius $=5 \mathrm{~cm}$ ) during the time it takes them to vertically settle $25 \mathrm{~cm}$ (optical pathlength), while quickly settling particles may be less likely to encounter the window. Below, we make a rough estimate of the minimum turbulent velocities encountered by the floats, and the corresponding maximum "unshaded" particle settling speeds given the 5:1 aspect ratio of the sampling volume. We ignored any wake effects stemming from interactions of the float itself with small-scale shear.

We made an order-of-magnitude estimate of the minimum turbulent velocities affecting settling particles, assuming that turbulence is isotropic and that the turbulent kinetic energy at the relevant spatial scales (from the float's size, order $1 \mathrm{~m}$, down to the Kolmogorov scale, $\sim 1 \mathrm{~cm}$ ) falls within the inertial subrange (Tennekes and Lumley, 1972). For regions sampled here, we conservatively assumed a minimum turbulent diffusivity of $\sim 10^{-5} \mathrm{~m}^{2} \mathrm{~s}^{-1}$ (Wunsch and Ferrari, 2004). We estimated a corresponding dissipation rate of turbulent kinetic energy of $\sim 10^{-9.5} \mathrm{~m}^{2} \mathrm{~s}^{-3}$ using the averaged buoyancy frequency at $\sim 1000 \mathrm{~m}$ (usually the depth of minimum stratification) and following the mixing-efficiency assumptions of Osborn (1980). We used this dissipation rate estimate to construct an inertial subrange velocity spectrum, which we integrated between spatial scales of the float size and the Kolmogorov scale $(\sim 1 \mathrm{~cm})$ to estimate the standard deviation of one-dimensional velocities explained by motions on those spatial scales (Tennekes and Lumley, 1972). We finally derived a minimum, mean turbulent velocity of $3.1 \times 10^{-4} \mathrm{~m} \mathrm{~s}^{-1}$. We estimate that this level of turbulence is sufficient to advect into the center of the sampling volume particles with mean settling speeds ranging through $\sim 130 \mathrm{~m} \mathrm{~d}^{-1}$. This velocity scale is representative of weakly stratified conditions in the ocean interior, away from topographic features, currents, and fronts, all of which would increase turbulent kinetic energy and the horizontal velocities of particles relative to the float (Gregg, 1987; Wunsch and Ferrari, 2004).

Finally, we need to estimate the POC-to-attenuation crosssection relationship (POC: $\sigma_{\mathrm{c}}, \mathrm{mg} \mathrm{OC} \mathrm{m}{ }^{-2}$ ) of the settling particles. Ultimately this should be determined empirically for sinking particles in the sampling environment, for instance using codeployed traps and drifting transmissometers. As an exercise here, we used literature values of POC $: \sigma_{\mathrm{c}}$ for suspended particles to derive the carbon flux associated 


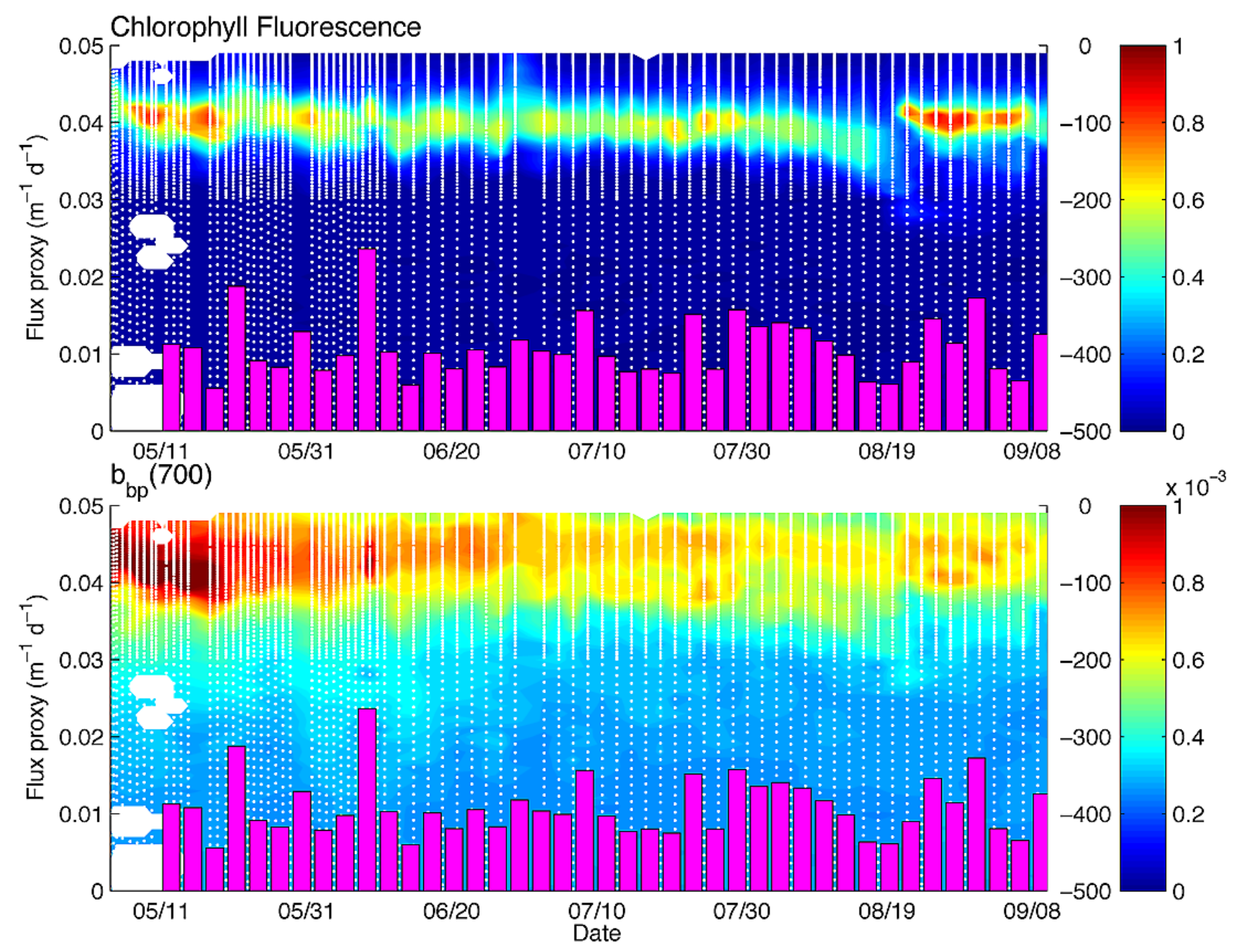

Fig. 9. Upper-water-column $(<500 \mathrm{~m})$ bio-optical data and simultaneous 3-day, bin-averaged, $1000 \mathrm{~m}$ flux proxy from float SS4. Upper panel: colors show $F_{\text {chl }}$ (faint dashed white lines show sample points) and magenta bars show cycle-mean flux proxy. Lower panel: colors show $b_{\mathrm{bp}}(700)$; magenta bars are the same as in upper panel. Both panels: left-hand axis denotes flux proxy magnitude, and right-hand axis denotes depth of contoured data.

with the mean, continuous component of the flux proxy $\left(0.01 \mathrm{~m}^{-1} \mathrm{~d}^{-1}\right)$ from the Atlantic floats (\#3-4; Table 2). Multiplication of the flux proxy $\left(0.01 \mathrm{~m}^{-1} \mathrm{~d}^{-1}\right)$ by the $0.25 \mathrm{~m}$ instrument pathlength yields the area-normalized rate of change of $\sigma_{\mathrm{c}}$, in this case $0.0025 \mathrm{~m}^{2} \mathrm{~m}^{-2} \mathrm{~d}^{-1}$. Literature values of POC: $\sigma_{\mathrm{c}}$ (summarized in Cetinić et al., 2012) cluster through the approximate range $300-600 \mathrm{mg} \mathrm{OC} \mathrm{m}^{-2}$, but to use these values, we must assume that the size and composition of suspended particles in the upper water column are representative of the sinking particle pool. We can illustrate the possible contribution of larger, sinking particles that are less common in the suspended pool following geometric optics assumptions (Van de Hulst, 1957) and using the POC-size relationship that McDonnell and Buesseler (2012) determined empirically for sinking particles at BATS. With these assumptions, we derived POC: $\sigma_{\mathrm{c}}$ values which depend on particle size and range from 200 to $4000 \mathrm{mg} \mathrm{OC} \mathrm{m}^{-2}$ (Fig. 11). Geometric optics assumptions are only appropriate for large, solid particles (such as fecal pellets or large, ballasted phy- toplankton cells) and not for aggregates of smaller particles, which would probably retain properties close to those of the suspended pool (Boss et al., 2009b).

Conversion of the $0.01 \mathrm{~m}^{-1} \mathrm{~d}^{-1}$ flux proxy to carbon units using the range of POC: $\sigma_{\mathrm{c}}$ values from suspended particles, and assuming $47 \%$ shading as discussed above, gave an estimated range of $1.4-2.8 \mathrm{mg} \mathrm{OC} \mathrm{m}^{-2} \mathrm{~d}^{-1}$ (at $1000 \mathrm{~m}$ ). POC flux estimates made with POC : $\sigma_{\mathrm{c}}$ values derived from geometric optics assumptions and sinking-particle POCsize relationships were larger, ranging from 0.9 to $19.5 \mathrm{mg}$ $\mathrm{OC} \mathrm{m}^{-2} \mathrm{~d}^{-1}$ depending on particle size (Fig. 11). The upper end of that range is clearly unrealistic as the largest particles are quite rare and they scatter light through angles smaller than the detector acceptance angle (Boss et al., 2009a). However, this estimate shows that the greater the contribution of large, solid particles to the sinking flux, the greater the magnitude of POC : $\sigma_{\mathrm{c}}$ relative to values based on small, suspended particles. For comparison, median POC fluxes from the $1500 \mathrm{~m}$ OFP trap time series ranged from 1.8 to $2.7 \mathrm{mg}$ 


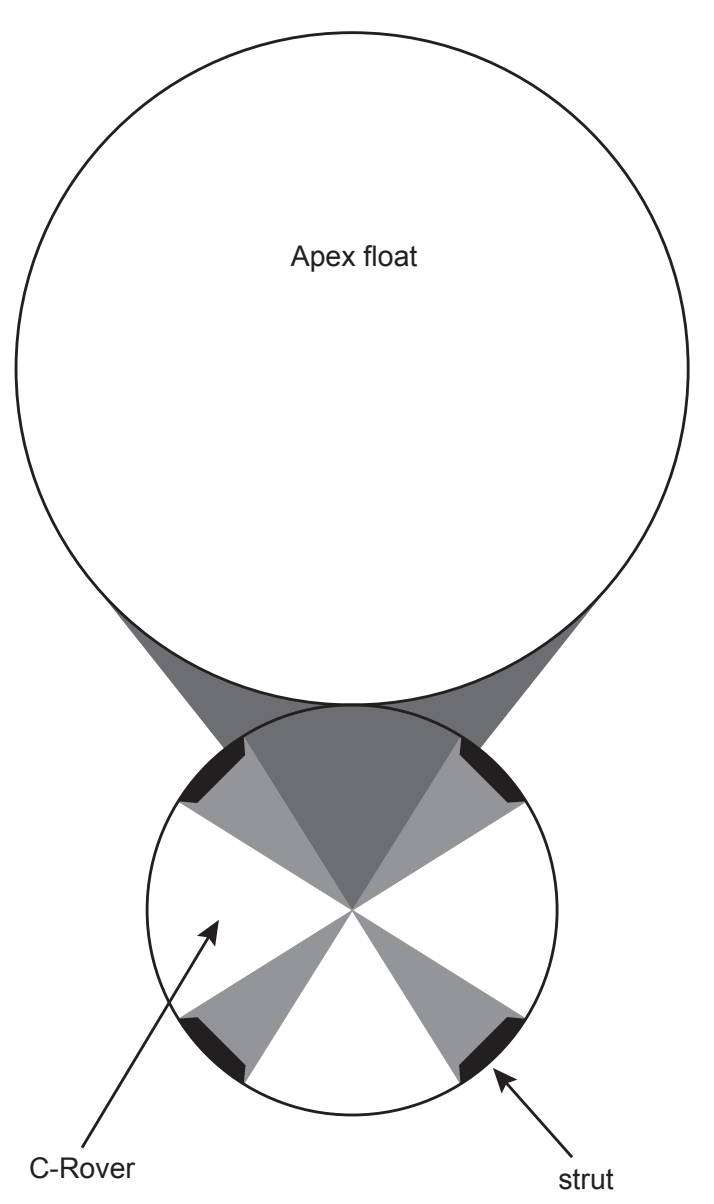

Fig. 10. Schematic showing cross section (in $x-y$ plane) of APEX float body and adjacent C-Rover transmissometer. Dark-gray area shows shading of the transmissometer by the float body, and lightgray areas show shading of the transmissometer by its four support struts. The unshaded fraction of the transmissometer circumference is $53.4 \%$.

$\mathrm{OC} \mathrm{m}^{-2} \mathrm{~d}^{-1}$ (from 31 May to 31 October and using the same data years as in Sect. 3.1, "Variability", above; Conte et al. 2001). This simplistic calibration of the flux proxy gives a POC flux range that compares quite well with direct observations (within a factor of 2 when depth differences are considered).

\subsection{Implications and next steps}

These autonomous observations of particle flux confirm the idea that particle export is characterized by large variability at small scales, as suggested by high-spatial-resolution ${ }^{234} \mathrm{Th}$ profiles and submesoscale-resolving biogeochemical models (Buesseler et al., 2009; Resplandy et al., 2012). In the oligotrophic systems sampled here, occasional highflux observations contributed disproportionately to the timeintegrated signal, but did not dominate it. This combination of small-scale, spatiotemporal variability and episodic, high-

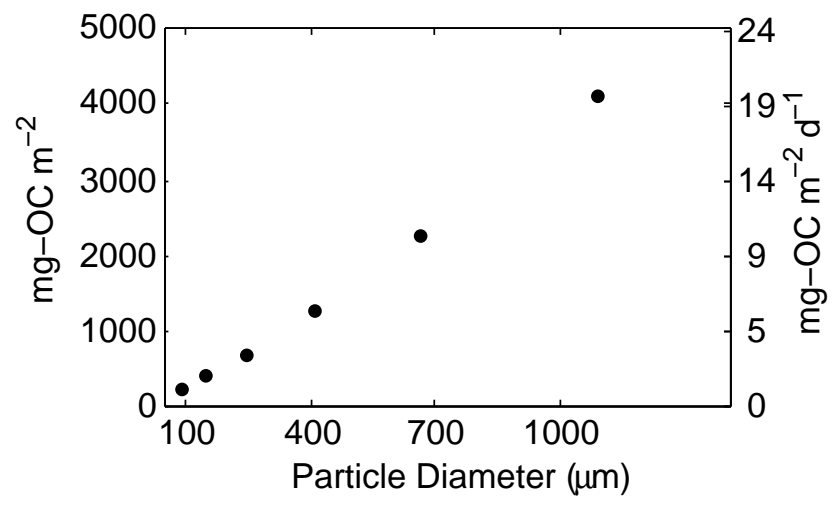

Fig. 11. Derived POC : attenuation cross section for large, solid particles as a function of particle size (left $y$ axis) and corresponding carbon flux for proxy value of $0.01 \mathrm{~m}^{-1} \mathrm{~d}^{-1}$, instrument pathlength of $0.25 \mathrm{~m}$, and $47 \%$ shading (right $y$ axis).

flux events underscores the utility of observations integrating particle flux over time (e.g., ${ }^{234} \mathrm{Th}$ deficit-based export), but it also highlights the importance of accounting for spatial variability in sampling designs targeting export flux. Observations of relationships between particle flux and ecosystem function will require further development of Lagrangian platforms with sensors that can resolve short spatiotemporal scales.

The particle flux proxy method developed here will only be truly quantitative once it is empirically calibrated against other methods. Regional, particle-size, and ecosystem-dependent changes in POC: $\sigma_{\mathrm{c}}$ are well documented for suspended particles in the water column (e.g., Bishop, 1999; Cetinić et al., 2012; Gardner et al., 2006), and likely extend to settling particles. The observations examined here are restricted to the oligotrophic ocean - application of this method in meso- or eutrophic systems, particularly over shelves where lithogenic particles are more prevalent, will require better constraints on settling-particle POC: $\sigma_{\mathrm{c}}$. Although the greatest need for high time-resolution particle flux data is conveniently in the upper thermocline, where ambient turbulent velocities are likely to be higher, we need to betterestablish the degree to which low turbulence limits collection of quickly settling particles, which may constitute a significant flux fraction. Continuous resuspension of the smallest settling particles is also possible, although in situ image sequences (e.g., Bishop and Wood, 2009, 2012) suggest that this effect may be small. Empirical calibration data spanning different times and depths will help constrain these sources of uncertainty. Hypotheses as to the cause(s) of the discontinuous flux component may be tested through comparison to "swimmer" carbon fluxes in simultaneously collected trap samples, or to in situ photographs of settled particles. Future calibration work in the laboratory and the field will provide empirical constraints on some of these relationships and 
allow for re-examination of the data presented here within a larger carbon-cycling context.

The bio-optical profiling floats whose measurements we analyze were deployed in well-characterized regions of the ocean, which allowed us to compare the new proxy to existing datasets and models. However, the great utility of autonomous platforms bearing simple sensors is that they can operate unattended for long periods of time in rough weather and in understudied and hard-to-access regions. In tandem with process studies clarifying the connections between physical processes, ecosystem function, and particle flux through the "twilight zone", autonomous floats bearing bio-optical sensors have the potential to transform our understanding of the ocean carbon cycle.

Acknowledgements. The authors would like to acknowledge the float development work of Teledyne-Webb Research, Inc.; WETLabs, Inc.; Satlantic, Inc.; and CLS America, as well as data management support from Bob Fleming at the University of Maine (supported by NASA (NOPP, NNX09AP51G)). We are also grateful for the time and assistance with float deployments provided by Rod Johnson and members of the BATS team, the MOBY team at Moss Landing Marine Labs, the Van Mooy lab at WHOI, and the captains and crews of the R/V Atlantic Explorer, the R/V Ka'imikai-O-Kanaloa, and the R/V Knorr. M.L.E. was supported by a WHOI Postdoctoral Scholar fellowship, and the floats used in this project were funded by the above NASA grant and by ONR (DURIP, N00014-10-1-0776).

Edited by: E. Marañón

\section{References}

Benitez-Nelson, C. R. and Moore, W. S.: Future applications of 234Th in aquatic ecosystems, Mar. Chem., 100, 163-165, 2006.

Bishop, J. K. B.: Transmissometer measurement of POC, Deep-Sea Res. Pt. I, 46, 353-369, doi:10.1016/S0967-0637(98)00069-7, 1999.

Bishop, J. K. B.: Autonomous observations of the ocean biological carbon pump, Oceanography, 22, 182-193, 2009.

Bishop, J. K. B. and Wood, T. J.: Particulate matter chemistry and dynamics in the twilight zone at VERTIGO ALOHA and K2 sites, Deep-Sea Res. Pt. I, 55, 1684-1706, doi:10.1016/j.dsr.2008.07.012, 2008.

Bishop, J. K. B. and Wood, T. J.: Autonomous exploration of carbon flux sedimentation in the twilight zone, Ocean Sciences Meeting, Salt Lake City, UT, 2012.

Bishop, J. K. B., Wood, T. J., Davis, R. A., and Sherman, J. T.: Robotic Observations of Enhanced Carbon Biomass and Export at 55 S During SOFeX, Science, 304, 417-420, doi:10.1126/science.1087717, 2004.

Boss, E. and Pegau, W. S.: The relationship of light scattering at an angle in the backward direction to the backscattering coefficient, Appl. Optics, 40, 5503-5507, 2001.

Boss, E., Slade, W. H., Behrenfeld, M., and Dall'Olmo, G.: Acceptance angle effects on the beam attenuation in the ocean, Opt. Express, 17, 1535-1550, 2009a.
Boss, E., Slade, W., and Hill, P.: Effect of particulate aggregation in aquatic environments on the beam attenuation and its utility as a proxy for particulate mass, Opt. Express, 17, 9408-9420, 2009b.

Briggs, N., Perry, M. J., Cetinic, I., Lee, C., D’Asaro, E., Gray, A. M. and Rehm, E.: High-resolution observations of aggregate flux during a sub-polar North Atlantic spring bloom, Deep-Sea Res. Pt. I, 58, 1031-1039, doi:10.1016/j.dsr.2011.07.007, 2011.

Buesseler, K. O. and Boyd, P. W.: Shedding light on processes that control particle export and flux attenuation in the twilight zone of the open ocean, Limnol. Oceanogr., 54, 1210-1232, 2009.

Buesseler, K. O., Bacon, M. P., Kirk Cochran, J., and Livingston, H. D.: Carbon and nitrogen export during the JGOFS North Atlantic Bloom Experiment estimated from ${ }^{234} \mathrm{Th}:{ }^{238} \mathrm{U}$ disequilibria, Deep-Sea Res., 39, 1115-1137, 1992.

Buesseler, K. O., Pike, S., Maiti, K., Lamborg, C. H., Siegel, D. A., and Trull, T. W.: Thorium-234 as a tracer of spatial, temporal and vertical variability in particle flux in the North Pacific, Deep-Sea Res. Pt. I, 56, 1143-1167, doi:10.1016/j.dsr.2009.04.001, 2009.

Burd, A. B., Hansell, D. A., Steinberg, D. K., Anderson, T. R., Arístegui, J., Baltar, F., Beaupré, S. R., Buesseler, K. O., DeHairs, F., Jackson, G. A., Kadko, D. C., Koppelmann, R., Lampitt, R. S., Nagata, T., Reinthaler, T., Robinson, C., Robison, B. H., Tamburini, C., and Tanaka, T.: Assessing the apparent imbalance between geochemical and biochemical indicators of meso- and bathypelagic biological activity: What the @\$!! is wrong with present calculations of carbon budgets?, DeepSea Res. Pt. II, 57, 1557-1571, doi:10.1016/j.dsr2.2010.02.022, 2010.

Calil, P. H. R. and Richards, K. J.: Transient upwelling hot spots in the oligotrophic North Pacific, J. Geophys. Res., 115, C02003, doi:10.1029/2009JC005360, 2010.

Cetinić, I., Perry, M. J., Briggs, N. T., Kallin, E., D’Asaro, E. A., and Lee, C. M.: Particulate organic carbon and inherent optical properties during 2008 North Atlantic Bloom Experiment, J. Geophys. Res., 117, C06028, doi:10.1029/2011JC007771, 2012.

Conte, M. H., Ralph, N., and Ross, E. H.: Seasonal and interannual variability in deep ocean particle fluxes at the Oceanic Flux Program (OFP)/Bermuda Atlantic Time Series (BATS) site in the western Sargasso Sea near Bermuda, Deep-Sea Res. Pt. II, 48, 1471-1505, 2001.

Emerson, S., Quay, P., Karl, D., Winn, C., Tupas, L., and Landry, M.: Experimental determination of the organic carbon flux from open-ocean surface waters, Nature, 389, 951-954, doi:10.1038/40111, 1997.

Gardner, W. D., Mishonov, A. V., and Richardson, M. J.: Global POC concentrations from in-situ and satellite data, Deep-Sea Res. Pt. II, 53, 718-740, doi:10.1016/j.dsr2.2006.01.029, 2006.

Gregg, M. C.: Diapycnal mixing in the thermocline: A review, J. Geophys. Res.-Oceans, 92, 5249-5286, doi:10.1029/JC092iC05p05249, 1987.

Henson, S. A., Sanders, R., and Madsen, E.: Global patterns in efficiency of particulate organic carbon export and transfer to the deep ocean, Global Biogeochem. Cy., 26, GB1028, doi:10.1029/2011GB004099, 2012.

Honjo, S., Manganini, S. J., Krishfield, R. A., and Francois, R.: Particulate organic carbon fluxes to the ocean interior and factors controlling the biological pump: A synthesis of global sediment trap programs since 1983, Progr. Oceanogr., 76, 217-285, 2008. 
Karl, D. M. and Knauer, G. A.: Swimmers: A recapitulation of the problem and a potential solution, Oceanography, 2, 32-35, 1989.

Karl, D. M. and Lukas, R.: The Hawaii Ocean Time-series (HOT) program: Background, rationale and field implementation, DeepSea Res. Pt. II, 43, 129-156, 1996.

Karl, D. M., Winn, C. D., Hebel, D. V. W., and Letelier, R.: Hawaii Ocean Time-Series Program field and laboratory protocols, 1990.

Karl, D. M., Church, M. J., Dore, J. E., Letelier, R. M., and Mahaffey, C.: Predictable and efficient carbon sequestration in the North Pacific Ocean supported by symbiotic nitrogen fixation, P. Natl. Acad. Sci., 109, 1842-1849, 2012.

Knap, A. H., Michaels, A. F., Steinberg, D. K., Bahr, F., Bates, N. R., Bell, S., Countway, P., Close, A., Doyle, A., Howse, F., Gundersen, K., Johnson, R. J., Little, R., Orcutt, K., Parsons, R., Rathbun, C., Sanderson, M., and Stone, S.: BATS Methods Manual, US JGOFS Planning Office, Woods Hole, 1997.

Knauer, G. A., Martin, J. H., and Bruland, K. W.: Fluxes of particulate carbon, nitrogen, and phosphorus in the upper water column of the northeast Pacific, Deep-Sea Res., 26, 97-108, 1979.

Lee, C., Wakeham, S. G., and Hedges, J. I.: The measurement of oceanic particle flux - are "swimmers" a problem?, Oceanography, 11, 34-36, 1988.

Martin, J. H., Knauer, G. A., Karl, D. M., and Broenkow, W. W.: VERTEX: carbon cycling in the northeast Pacific, Deep-Sea Res., 34, 267-285, 1987.

McDonnell, A. M. P. and Buesseler, K. O.: A new method for the estimation of sinking particle fluxes from measurements of the particle size distribution, average sinking velocity, and carbon content, Limnol. Oceanogr.-Methods, 10, 329-346, 2012.

Michaels, A. F., Bates, N. R., Buesseler, K. O., Carlson, C. A., and Knap, A. H.: Carbon-cycle imbalances in the Sargasso Sea, Nature, 372, 537-540, 1994.
Osborn, T. R.: Estimates of the Local Rate of Vertical Diffusion from Dissipation Measurements, J. Phys. Oceanogr., 10, 83-89, 1980.

Proctor, C. W. and Roesler, C. S.: New insights on obtaining phytoplankton concentration and composition from in situ multispectral Chlorophyll fluorescence, Limnol. Oceanogr.-Methods, 8, 695-708, 2010.

Resplandy, L., Martin, A. P., Le Moigne, F., Martin, P., Aquilina, A., Mémery, L., Lévy, M., and Sanders, R.: How does dynamical spatial variability impact 234Th-derived estimates of organic export?, Deep-Sea Res. Pt. I, 68, 24-45, doi:10.1016/j.dsr.2012.05.015, 2012.

Siegel, D. A., Fields, E., and Buesseler, K. O.: A bottom-up view of the biological pump: Modeling source funnels above ocean sediment traps, Deep-Sea Res. Pt. I, 55, 108-127, 2008.

Steinberg, D. K., Carlson, C. A., Bates, N. R., Johnson, R. J., Michaels, A. F., and Knap, A. H.: Overview of the US JGOFS Bermuda Atlantic Time-series Study (BATS): a decade-scale look at ocean biology and biogeochemistry, Deep-Sea Res. Pt. II, 48, 1405-1447, doi:10.1016/S0967-0645(00)00148-X, 2001.

Tennekes, H. and Lumley, J. L.: First Course in Turbulence, MIT Press, 1972.

Van de Hulst, H. C.: Light scattering by small particles, John Wiley and Sons, New York, 1957.

Wunsch, C. and Ferrari, R.: Vertical mixing, energy, and the general circulation of the oceans, Annu. Rev. Fluid Mech., 36, 281-314, 2004.

Zhang, X., Hu, L., and He, M.-X.: Scattering by pure seawater: Effect of salinity, Opt. Express, 17, 5698-5710, 2009. 